\title{
Study of the Aerodynamic Process and Its Impact on Cotton Transportation Process through the Cotton Pipeline
}

\author{
Shokhsanam Imomalieva, Anvar Makhkamov \\ Namangan Institute of Engineering Technology, Namangan, Uzbekistan \\ Email: imomaliyeva.shoxsanam.94@mail.ru, anvarmaxkamov@gmail.com
}

How to cite this paper: Imomalieva, S. and Makhkamov, A. (2021) Study of the Aerodynamic Process and Its Impact on Cotton Transportation Process through the Cotton Pipeline. Engineering, 13, 667-676. https://doi.org/10.4236/eng.2021.1312048

Received: October 12, 2021

Accepted: December 21, 2021

Published: December 24, 2021

Copyright (๑) 2021 by author(s) and Scientific Research Publishing Inc. This work is licensed under the Creative Commons Attribution International License (CC BY 4.0).

http://creativecommons.org/licenses/by/4.0/

\section{(c) (i) Open Access}

\begin{abstract}
The article provides a theoretical analysis of the velocity distribution and distribution in the cross section of the pipe during the transportation of cotton. It studied the factors that move air and transport material in a pneumatic pipeline, developed a mathematical model and built graphs. The effect of pressure on the ease of construction of pipes for air transportation of raw cotton and the speed distribution in the process of transporting cotton, as well as the factors that cause pressure loss in the shells of pipes were studied. So, if the expansion after the air pipe is expanded $\vartheta_{1}>\vartheta_{2}$ (5), we will introduce $K_{1}=0$ and the beating coefficient $\xi$. If the current narrows before burdening, then we enter $K_{1}=1$ and the input soften rate from the formula $\xi$. The air flow is moving upwards below the slope and the longer the pipe is the air flow is so significant (strong). The flow of air is divided into laminar and turbulent streams according to leakage. The procedure for transportation of raw cotton using air will move the turbulent the sidelines, interacts with the layers. If the turbulent passes in a well-round smooth passenger-pipes, the number of critical Reynolds can be delivered to 200,000. The process of transporting cotton in pnevmotransport is far from the laminary regime in far away and stronger mode.
\end{abstract}

\section{Keywords}

Cotton, Airstream, Laminar Current, Turbulent Flow, Speed, Separator, Lamination, Movement, Label Surface

\section{Introduction}

It is well known that there are still some shortcomings in spite of the improve- 
ment of technological machines and equipment, including the improvement of the pnevmotransport. For example, as far as possible, during the air transport, the cotton division and theoretical foundations of other events were not explored. Studies, mainly, cover particular problems and components of the device, which contain specific components, in some cases, which are incompatible with each other. The previously held research requires the development of the theory and practice of cotton, to maintain the preliminary quality indicators of cotton products and reduce the cost of the product. The ginning industry has led to a widespread spreading industry with the simplicity of the airpipeline, without destroying it to the places designated in any complex areas, depending on the areas set in any complex areas, sanitation [1].

Steel air pipes are used in the ginner industry, mainly diameter of $200-600$ $\mathrm{mm}$. This is used in the transportation of cotton fiber in air flow, per $200-200$ $\mathrm{mm}$ of a lane of the $300 \mathrm{~mm}$, a $400 \mathrm{~mm}$ of an airpipeline. The main reason for wide use of airpipeline device is its reliable operation, the minimum use of cotton, the compact and flooding tools are possible, servicing and repairing it. It is also carried out by air flow to the trembling of the cotton and helps the loss of a certain amount of humidity. In addition to the separation of cotton from the air, the initial cleaning of cotton is supplied by small dirty mixtures and dust [2] [3]. With the help of air, the air inside the device is forced to move the material mainly during its movement. The movement of air inside the pipe is provided by air-spraying machines fans.

With the help of the air, the absorption of the device is divided into a sweating, blowering and sucker species according to air pressure change, when transporting cotton with air transport, the movement of the air is in the same type in the pipes. Turbulent stream $R>2220$. If you slowly increase the speed of resting air, the transition from laminar is observed in re $=5000$ [4].

\section{Materials and Methods}

Initially, we see cotton only in pipes of cotton. At the time of air transportation by air, the movement of the air is in the same type in the pipes. Turbulent Stream $R>230$ (Figure 1). If you begin to quickly increase the speed of the heavy air, it is possible to switch from laminar arrangement in re $=5000$. We can see changes to the air speed in the tranversity of the circular air pipeline [5].

Since there is a unit of stickiness in the pipe, the air begins to strike on the

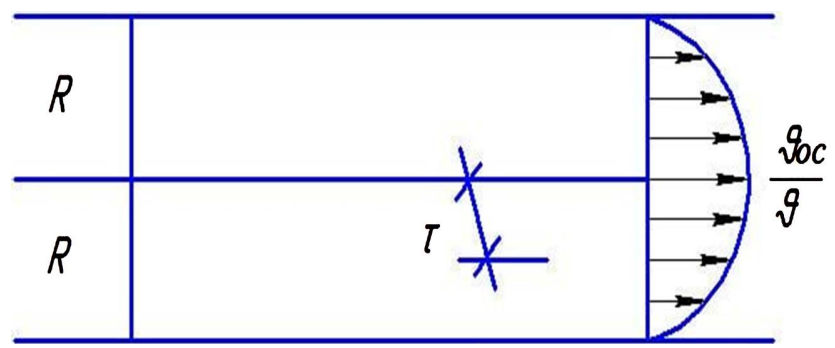

Figure 1. Change the speed of the air in the tranversity of air pipes. 
pipe walls and slow down. Therefore, as the speed of $\vartheta^{1}$ is contingent in the air pipeline, the aircraft will have the largest $\vartheta_{y \kappa}$. We will define $\vartheta$ and $\vartheta_{y \kappa}$ the expenses that it is connected to each other.

We will see the turbulent flow. According to L. Prandtl, the impending voltage is found as follows.

$$
\tau=p \ell w a y^{2}\left(\frac{\mathrm{d} \vartheta}{\mathrm{d} r}\right)^{2}
$$

here 1-length

$$
\mathrm{d} \vartheta=\sqrt{\frac{r}{\rho \cdot \ell_{n}^{2}}} \mathrm{~d} r .
$$

We determine $\tau$ the following of the size of this (3).

$$
\mathrm{d} \vartheta=\sqrt{\frac{\left(\rho_{1}-\rho_{2}\right)^{2} r}{z \ell \rho \cdot \ell_{n}^{2}}}
$$

This equation is an unknown function from the transition of the integration $t_{n}$. Today, this issue has been accepted by various hypotheses relative to the existence of several solutions. $\mathrm{H}$ hipothesa, $L_{n}$ company competitions extracted advice.

$$
\ell_{n}=x(R-r)
$$

In this case, the fact that $x$ is coefficient. However, for a turbulent flow, the change in velocity relative to the radius has not been determined theoretically. We use the identified size through experiments as a result of this

$$
\vartheta=\vartheta u k\left(1-\frac{r}{R}\right)^{\frac{1}{n}}
$$

$\frac{1}{n}$. The level indicator decreases with an increase in the turbulent flow. Analyze this equality, that is, the increase in the growth of air leads to an equal rate equal to $A l$ the air pipeline cut. $\frac{1}{n} \rightarrow 0 \quad \vartheta=\vartheta_{y p}$ accounts may be accepted in books $n$ and 7. [6].

When transported at moderate speeds in an air transport pipeline, heavy objects and cotton are strongly affected by the walls of the air pipeline at its bottom. Friction occurs between the cotton and the air duct walls, causing the fibers to roll, stick, and swell. When the air flow velocity is greater than $28 \mathrm{~m} / \mathrm{s}$, the cotton is distributed more evenly across the cross section of the air duct. In such conditions, the media is subject to a state of view. If the airflow speed decreases from $25.0 \mathrm{~m} / \mathrm{s}$, more of the material will start to move at the bottom of the air pipe. The results of monitoring cotton by air traffic test showed that raw materials will not be transmitted evenly to air transport pipelines [7]. As a result, the cotton moves inside the air duct, in some places collected, and in some places sparsely divided into certain pieces. 
On high unevenness, the cotton is placed in layers in the form of layers on the surface of the tape, with great density and weight, and closes a certain part of the mouth of the pipe when it enters the air duct. As a result, air velocity and dynamic pressure decrease, while static pressure increases [8]. Degrades in the fragment of cotton in the pipe meet statients and air particles in the cotton fracture, and begin to move towards the ventilator, and in the process of transporting it is larger behind it in the transportation process. Aerodynamic shadow is formed. Here, the resistance force, which is formed by the adhesion of cotton to the inner surface of the air duct, is added to the line of resistance forces, and the cotton stops at the bottom of the air duct.

As a result, the air pipeline is covered and congestion is occurring [9] [10]. The process of transporting the material in air transport means the movement of this multidisciplinary environment in a particular direction. The moving component includes air, cotton and mineric mixtures in our example. However, in order to simplify analysis of the transportation process, it is considered to be only two forms (Figure 2). The forces affected by the airstream movement of a cotton groan is more explored. They are mainly taken into account, the strength of resistance, inertic power and weight. In general, the action equation in the air transport pipeline of the cotton can be said:

$$
m \frac{\mathrm{d} u}{\mathrm{~d} t}=\sum F_{i}
$$

Here: $m$-mass of the piece, $\mathrm{kg} ; u$-its speed, $\mathrm{m} / \mathrm{s} ; \sum F_{i}$ The sum of the forces affected by a cotton-piece cotton, $\mathrm{H}$.

A simple scheme of the aerodynamic device and air pressure directions.

Distribution of aerodynamic forces and air speeds in the air pipeline transverse distribution. In our research, we have identified the speeds of cotton and air at the head of the piper. The speed of cotton is close to the first $1 \mathrm{~m}$ distance to the speed of the component tape. The current component tape rate is $3 \mathrm{~m} / \mathrm{s}$. At the end of the distance of $1 \mathrm{~m}$, the cotton rate reaches $4.5 \mathrm{~m} / \mathrm{s}$. If we accept speed value, $V_{M}=3.5 \mathrm{~m} / \mathrm{s}$. In that case, when work productivity $p=2.78 \mathrm{~kg} / \mathrm{s}, I$ $=1 \mathrm{~m}$.

$$
M=\frac{2.78 \times 1}{3.5}=0.8 \mathrm{~kg}
$$

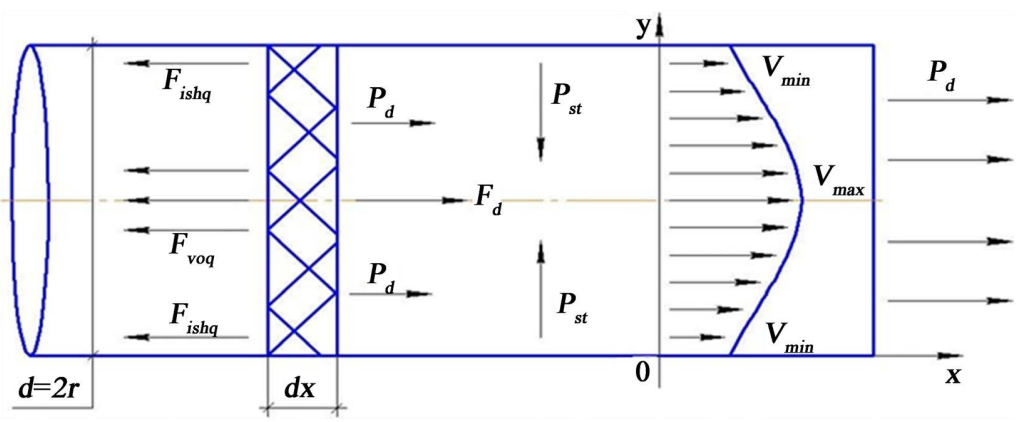

Figure 2. Distribution of aerodynamic forces and air speeds in the air pipeline. 
$P=3.33 \mathrm{~kg} / \mathrm{s}, l=1 \mathrm{~m}$

$$
M=\frac{3.33 \times 1}{3.5}=0.95 \mathrm{~kg}
$$

According to the number of numbers, only $0.80-0.95$ of the air pipeline is of board $1 \mathrm{M}$.

Now consider a right-angled elbow with a transverse cross-section. We will hold 1-1 up to the cutter and 2 to section where the current expands and all cut is filled [11] [12] (Figure 3).

According to Bernulli equation:

$$
P_{1}+\frac{\rho \vartheta_{1}^{2}}{2}=P_{2} \frac{\rho \vartheta_{2}^{2}}{2}+\Delta P
$$

From this:

$$
\Delta P=P_{1}-P_{2}+\frac{\rho}{2}\left(\vartheta_{1}^{2}-\vartheta_{2}^{2}\right)
$$

We will consider the size between two incisions and walls of the elbow and the projection of the elbow after the burial is written to the proportion of movement [13].

$$
P_{1} F_{1} \cos \theta+r_{1} \varphi_{1} \sin \theta-P_{2} F_{2}=\rho F_{2} \vartheta_{2}\left(\vartheta_{2}-\vartheta_{1} \cos \theta\right)
$$

Here, $\tau_{1}-1-1$ replacing the surface average $\phi$ pressure from the surface $\tau_{1}-$ to the corner height of; $r_{1}<P_{1}+K_{1} \frac{\rho \vartheta_{1}}{2}$ and $\varphi_{1} \sin \theta=F_{2}-F_{1} \cos \theta$ short and is taken (Figure 4).

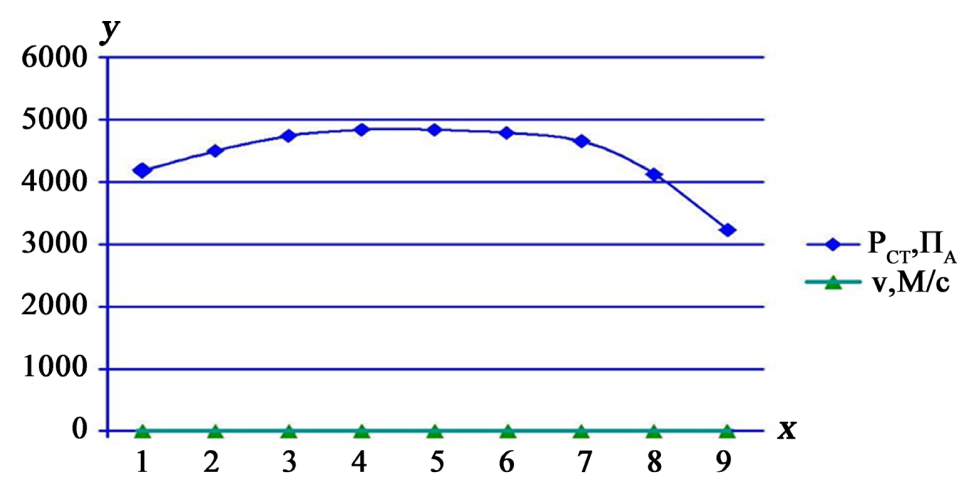

Figure 3. The connection between the air speed is the connection between Rst.

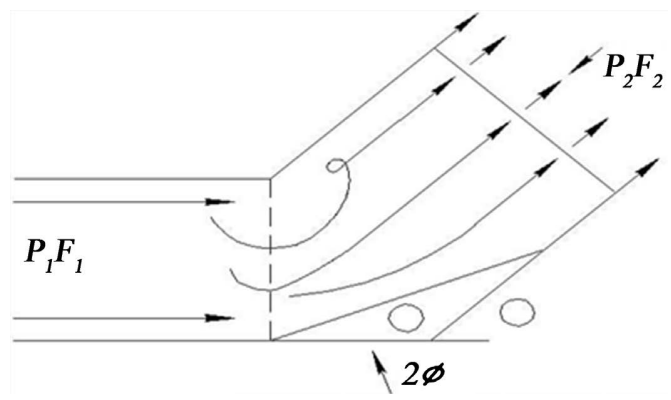

Figure 4. The right angular elbow changed transversal cut. 


$$
\begin{aligned}
& P_{1} F_{1} \cos \theta+P_{1}\left(F_{2}-F_{1} \cos \theta\right)-P_{2} F_{2} \\
& =P F_{2} \vartheta_{2}\left(\vartheta_{2}-\vartheta_{1} \cos \theta\right)-K_{1}\left(F_{2}-F_{1} \cos \theta\right) \frac{\rho \vartheta_{1}^{2}}{2}
\end{aligned}
$$

This equation is reducing equivalent to $F_{2}$ and written the following

$$
P_{1}-P_{2}=\frac{\rho}{2}\left(2 \vartheta_{2}^{2}\left(\vartheta_{2}-\vartheta_{1} \cos \theta\right)-K_{1}\left(1-\frac{F_{1}}{F_{2}} \cos \theta\right) \vartheta_{1}^{2}\right)
$$

We write this equation according to $\frac{F_{1}}{F_{1}}=\frac{\vartheta_{2}}{\vartheta_{1}}$ equality of value changes.

$$
P_{1}-P_{2}=\frac{\rho}{2}\left(\vartheta_{2}^{2}\left(\vartheta_{2}-\vartheta_{1} \cos \theta\right)-K \vartheta_{1}\left(\vartheta_{1}-\vartheta_{2} \cos \theta\right)\right)
$$

From the burning this equality we will get below.

$$
\Delta P=\frac{\rho}{2}\left(\vartheta_{1}^{2}-r \vartheta_{1} \vartheta_{2} \cos \theta+\vartheta_{2}^{2}-K_{1} \vartheta_{1}\left(\vartheta_{1}-\vartheta_{2} \cos \theta\right)\right) \quad \text { [14] }
$$

1. If the expansion after the air pipe is expanded $\vartheta_{1}>\vartheta_{2} \quad$ (5), we will introduce $\mathrm{K} 1=0$ and the beating coefficient $\xi$.

2. If the current narrows before burdening, then we enter $\mathrm{K} 1=1$ and the input soften rate from the formula $\xi$.

3. If the elbow is cut (5), the formula is the following as follows, $\vartheta_{1}=\vartheta_{2}=\vartheta_{0}$ corresponds to angle elbow of the corresponding formulas. It is also possible to write to the circus elbows as follows.

$$
\begin{aligned}
& \text { 1) } \Delta P=\eta_{x} \frac{\rho}{2}\left(\vartheta_{1}^{2}-2 \vartheta_{1} \vartheta_{2} \cos \theta+\vartheta_{2}\right) ; \xi=\eta_{x}\left(1-2 \frac{F_{1}}{F_{2}} \cos \theta+\frac{F_{1}^{2}}{F_{2}^{2}}\right) \\
& \text { 2) } \Delta P=\eta_{x} \frac{\rho}{2}\left(\vartheta_{2}-\vartheta_{1} \cos \theta\right) ; \xi=\eta_{x}\left(1-\frac{F_{2}}{F_{1}} \cos \theta\right) \\
& \text { 3) } \Delta P=(2-K) 2 \sin ^{2} \frac{\theta}{2} \frac{\rho \vartheta^{2}}{2} ; \xi=(2-K) 2 \sin ^{2} \frac{\theta}{2}
\end{aligned}
$$

It is known that the main trunk section is made of $2-3 \mathrm{~mm}$ steel tuna or asbestosic cement cemented pipes, a diameter of $400-500 \mathrm{~mm}$.

Friction flow between the pipe wall with the airline within the airline inside the air has a negative impact (Figure 5). The air pressure is partially used to overcome

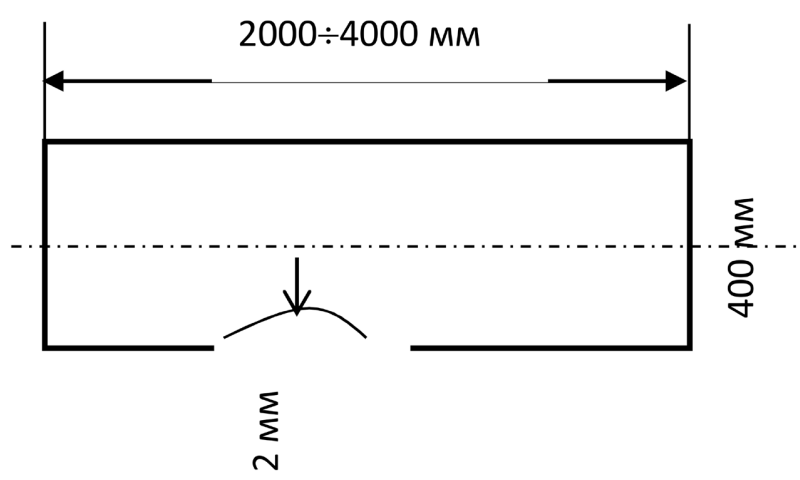

Figure 5. A pipe scheme. 
This friction force. Due to the influence of this power, the pipe does not distribute air flow speeds along the transverse, and the dynamic pressure is not a flat, and the speed and speed of the wall decreases between the pipeline (Figure 6).

As a result of a flat distribution of the pressure power, the transverse force is formed from the pipe wall.

The value of this power is nulled in the pipe center, while the wall level is achieved its maximum. When transporting materials using air, this transverse force acts as a lifting force [15]. Dynamic pressure and air speed are interrelated and it is necessary. However, it is not the air velocity that causes the pressure, but the exact pressure velocity.The relationship between them is as follows (Table 1):

$$
P_{\text {дин }}=\rho_{x} \cdot \frac{V_{x}^{2}}{2}
$$

In this case, $\rho_{x}$-air density, $-\mathrm{kg} / \mathrm{m}^{3}$ (equivalent to normal temperature) $\rho_{x}=1.2 \mathrm{~kg} / \mathrm{m}^{3}$

$V_{x}$-Air speed,m/s;

The dynamic pressure piped is influenced by the entire transversection cut and causes fermentation force:

$$
P_{\text {дин }}=\frac{F_{a}}{S_{\kappa}}
$$

In this case, $F_{a}-$ Aerodynamic force (pressure power), $\mathrm{H} ; S_{k}-$ Pipe the surface of the transverse, $\mathrm{m}^{2}$;

For pipes:

$$
S_{\kappa}=\frac{\pi d^{2}}{4}
$$

Given the (11) (10) and (12)

$$
F_{a}=P_{\partial u t} \cdot S_{\kappa}=P_{\partial u t} \cdot \frac{\pi d^{2}}{4}=\rho_{x} \cdot \frac{V_{x}^{2}}{2} \cdot \frac{\pi d^{2}}{4}
$$

The results are as follows:

$$
F_{a}=0.125 \cdot \pi \cdot \rho_{x}\left(V_{x} \cdot d\right)^{2}
$$

We analyze the equation in a graphic way (Figure 7).

Dependence of aerodynamic power to air speed and pipe diameter.
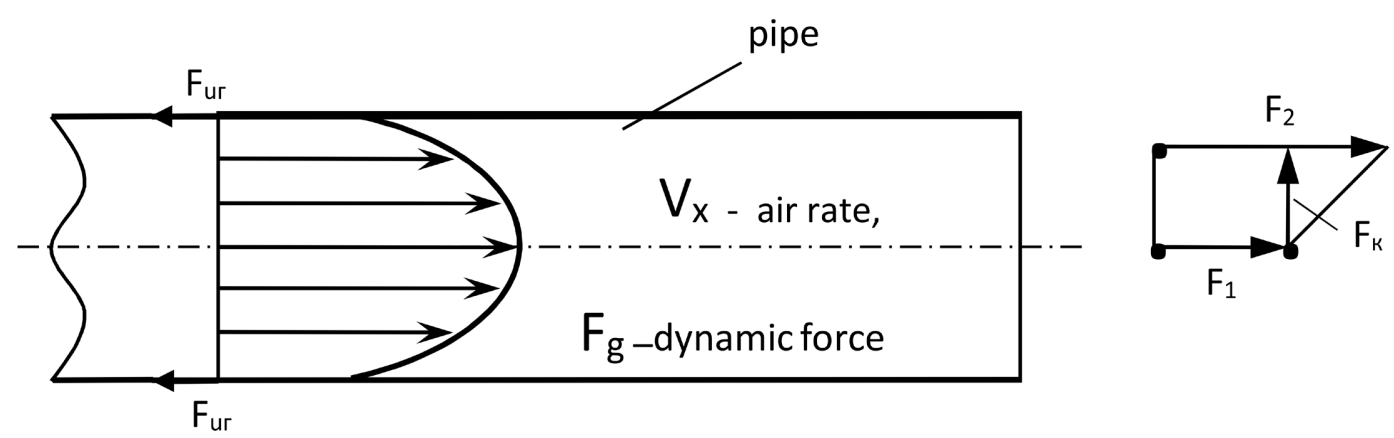

Figure 6. Formed along the transverse of the pipe. 
Table 1. Dependence of aerodynamic power to air speed and pipe diameter.

\begin{tabular}{cccccc}
\hline$V$ & 0 & 10 & 10 & 20 & 20 \\
Д & 0 & 0,3 & 0,4 & 0,3 & 0,4 \\
$F_{a}$ & 0 & 4,2 & 7,5 & 16,8 & 30,1 \\
\hline
\end{tabular}

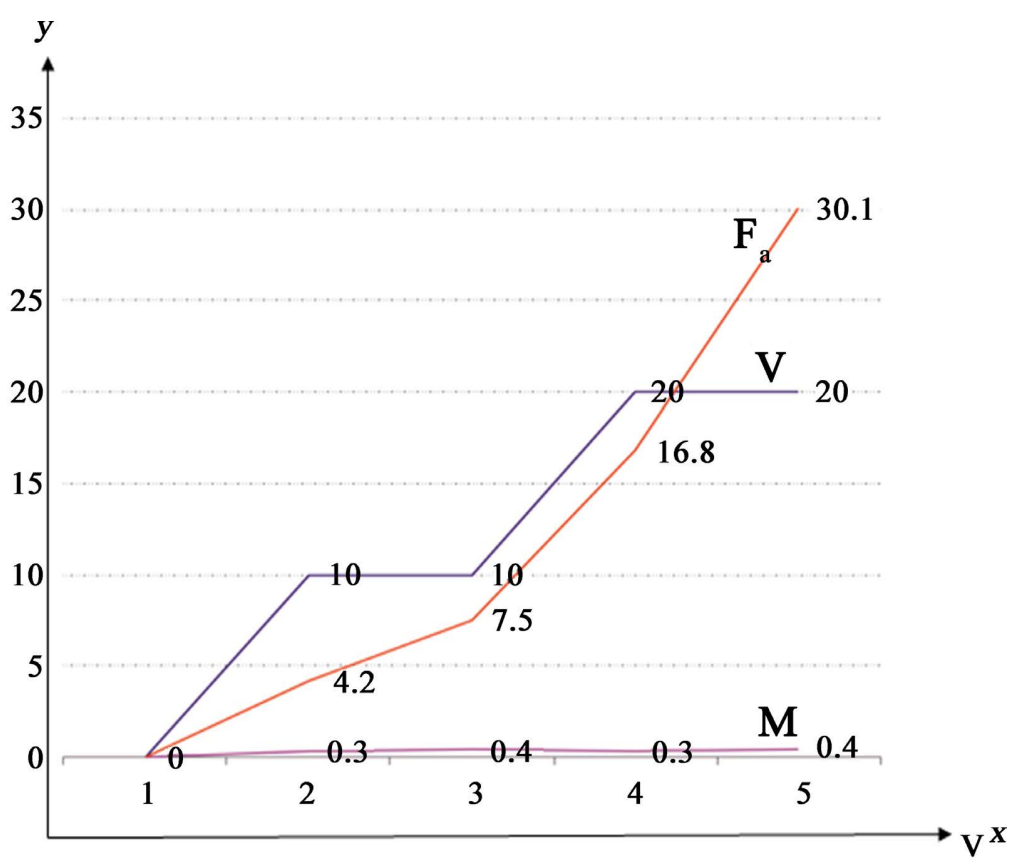

Figure 7. Schedule of aerodynamic force depending on the air speed and the pipe diameter.

The increase in speed leads to a sharp increase in aerodynamic power. For example, if the pipe is full of the pipe diameter to $10 \mathrm{n}$ full of $10 \mathrm{~m} / \mathrm{s}$, the aerodynamic force rises to $30 \mathrm{n}$.

When the pipe shrinks the diameter of the pipe, when the medium is D-0.3, its quantity decreases sharply, in the intensity of change of aerodynamic power. For example, when air speed is $10 \mathrm{~m} / \mathrm{s}$, the force is yielded $4.5 \mathrm{n}, 20 \mathrm{~m} / \mathrm{s}$.

Work with pnevmotransport is the same according to the size of the same aerodynamic force:

$$
\mathrm{d} A=P \cdot \mathrm{d} L
$$

Here: L-Migration Distance, $\mathrm{m}$.

The capacity spent on the transfer of the airpipe

$$
\begin{gathered}
N=\frac{\mathrm{d} A}{\mathrm{~d} t} \quad(24), \text { or according to (25), } \\
N=\frac{P \cdot \mathrm{d} L}{\mathrm{~d} t} \quad \text { (25) will be (26). }
\end{gathered}
$$

\section{Conclusions}

1) The air flow is moving upwards below the slope and the longer the pipe is the air flow is so significant (strong). The flow of air is divided into laminar and 
turbulent streams according to leakage. The procedure for transportation of raw cotton using air will move the turbulent the sidelines, interacts with the layers.

2) If the turbulent passes in a well-round smooth passenger-pipes, the number of critical Reynolds can be delivered to 200,000. The process of transporting cotton in pnevmotransport is far from the laminary regime in far away and stronger mode.

3) When transported at medium speeds in an air transport pipe, strong contact with heavy objects and cotton air pipe walls at its bottom causes static pressure. Therefore, the air flow rate should be uninterrupted at high speeds.

4) Uneven transmission of cotton to the air duct and changes in its humidity and volume density of cotton leads to a decrease in the efficiency of devices in the pneumatic transport system. To ensure the continuity of this process, the transmission of cotton to the air duct evenly and at normal humidity ensures the efficient operation of the devices [16].

\section{Conflicts of Interest}

The authors declare no conflicts of interest regarding the publication of this paper.

\section{References}

[1] Jabbarov, G.J. (1987) Preliminary Processing Technology for Chewing Cotton.

[2] Sarimsakov, O.S. (2017) Dissertation on "Scientific-Based Technology of Transportation of Raw Cotton and Transportation of Air Transport".

[3] Davydbaev, X.K. (1974) Isslidovanie I Vyborimalnыx Parametric Bunkera-Nakopitya Dlya Intensification of the Plania Xlopkom-sirTistritional Boutota Djinov I Eurtitelnyx Mash. Diplomat International School, Tashkent, 56 p.

[4] Khasanov, M.R., Makhkamov, R.G. and Nishanov, A.N. (1992) Zomaniatorrefaction for Poranting Cotton-in Ponevmodnisov with Ginning Systems. Sebbornaka Guchnyx Troud Tashpi, Tashkent, 36-39.

[5] Hamidov, S.S. (2005) Aerodynamics. Samarkand Publishing House, 27-28.

[6] Fabrillant, I.Y. (1984) Aerodynamics. Izgotovleniya Nauka, 75-78 p.

[7] Husanov, S.M. (2014) Improving the Reliability of the Pnevmotransport Device. Institute of Engineering and Technology of the Master of Engineering and Technology.

[8] Makhkamov, A.M., Khusanov, C.M., Muradov, R.M. and Imomaliyeva, S.F. (2020) The Oretic Observation of the Cotton Movement in the Operating Camera of the New Separator. International Journal of Psychosocial Rehabilitation, 24, 6356-6364. https://doi.org/10.37200/IJPR/V24I5/PR2020619

[9] Akramjanov, d., Mahkamov, A.U. and Imamalieva, S. (2020) Simulation of the Program Simulation of the Process of Separation of Cotton Raw Cotton. The DGU of IMA DGU 08906 Copyright 10.08 .

[10] Akramjanov, D., Mahkamov, A., Khusanov, S. and Imamalievash, T. (2020) Ima of Imma’s. DGU 09395 Copyright 16.10.

[11] Abduvahidov, M., Akramjonov, D., Rakhimberdiev, D. and Makhzamov, A. (2019) Isslidovanie Voprasov Analyticheskogo Operedeleniya Parameterov Estware Pack- 
age Cleans. Universon Texnicheskie Nausi, 4, 16-20.

https://doi.org/10.1007/s11298-019-7340-2

[12] Husanov, S., Makhkamov, A., Muradov, A. and Muradov, R.C. (2019) From the Air Flow under the Influence of the Center's Refuge. Scientific and Technical Journal at the Namangan Institute of Engineering Technology, 3, 59-64.

[13] Abduvahidov, M., Makhkamov, A., Siddikov, A. and Kholmirzaev, F. (2018) Isslidovanie Analyticheskogo Opredleleniya Parameters Gestkosti Packet Constructs. International Conference Science and Practice: A Nev Level of Integration in the Modern World, 143-146.

[14] Pre-Khusanov, N., Khusanov, S., Makhkamov, A. and Muradov, R.R. (2018) Ways to Increase the Efficiency of the Stone Handle Device. NamMti International Conference "During the Period of Innovative Development", 103-106 p.

[15] Khusanov, S., Makhkamov, A. and Muradov, R. (2018) Increase the Useful Surface of the Linge Surface of the Cable Surface of the Cotton Separator Device. NamMti International Conference "During the Period of Innovative Development", 106-108 p.

[16] Denur, J. (2019) Aerodynamic versus Ballistic Flight. Open Journal of Fluid Dynamics, 9, 346-400. https://doi.org/10.4236/ojfd.2019.94023 